\title{
EL DISCURSO PUBLICITARIO DESDE EL ENFOQUE DE LOS DERECHOS HUMANOS
}

\author{
Daniel Antonio García HuERta ${ }^{1}$
}

REsumen. La publicidad comercial, durante mucho tiempo, ha sido considerada como el ejercicio de acciones exclusivamente de carácter comercial o propagandístico, dejando de lado algunos otros aspectos que resultan de interés y beneficio para la sociedad. El presente documento retoma la perspectiva del discurso publicitario desde un enfoque de derecho humanos, analizando su ejercicio y desarrollo en el marco de la libertad de expresión y el derecho a la información, así como su utilidad en la promoción y educación de los derechos humanos.

Palabras clave. Derechos humanos, libertad de expresión, derecho a la información, publicidad, discurso publicitario, medios de comunicación, anuncios publicitarios.

Abstract. Commercial advertising, for a long time, has been considered as the exercise of commercial and propaganda actions, ignoring some other aspects of interest and benefit to society. This paper adresses the perspective of commercial speech from a human rights' scope, analyzing it's exercise and development in the framework of freedom of expression and right to information and its usefulness in the promotion and education of human rights.

KEY WORDS. Human rights, freedom of expression, right to information, advertising, commercial speech, mass media.

Sumario. I. Introducción; II. Publicidad y tipos de publicidad; III. La publicidad comercial como ejercicio del derecho a la libertad de expresión; IV. La publicidad comercial en el marco del derecho a la información; v. Publicidad comercial y medios de comunicación masiva: mecanismos de regulación y autorregulación; VI. La publicidad comercial como mecanismo de educación y promoción en derechos humanos; viI. Conclusiones.

1 Licenciado en Derecho por la UNAM y Maestro en Derechos Humanos y Garantías por el ITAM. Ha cursado estudios de especialización en Derechos Humanos en universidades de EUA y Colombia. 


\section{INTRODUCCIÓN}

T a publicidad, o el discurso publicitario que la enmarca, ha sido considerada como una actividad de carácter puramente comercial que persigue fines de lucro o de empresa y cuyo ejercicio en nada contribuye a la formación de valores en el marco de una ciudadanía responsable y respetuosa de los derechos humanos. Esta concepción ha servido como base para argumentar que el ejercicio de la publicidad, y en especial aquélla de carácter comercial, requiere de un estándar menor de protección, o incluso, que no merece ser protegida por la legislación y el Estado en virtud de que en nada fomenta la discusión de temas de interés general o utilidad para la sociedad. Sin embargo, la adopción y defensa de este tipo de argumentos deja de lado algunos otros elementos que merecen ser considerados en el marco de una sociedad democrática y respetuosa de los derechos humanos tales como el que la transmisión de mensajes publicitarios puede constituir un mecanismo para el goce y ejercicio de algunos derechos como la libertad de expresión y el derecho a la información, entre otros.

A través de las siguientes líneas se exponen algunas razones que permiten sostener que la publicidad comercial no necesariamente responde únicamente a fines de carácter económico o a técnicas de persuasión que fomenten en las personas la necesidad de adquirir determinados bienes o servicios, perpetuando actitudes consumistas, individualistas y utilitarias. Por el contrario, el presente documento se centra en el desarrollo de ideas que permitan concebir a la publicidad comercial como el ejercicio de derechos humanos relacionados con el fortalecimiento del sistema democrático en una sociedad plural, y sostiene la necesidad de que el Estado garantice la existencia de un estándar de aseguramiento y protección del discurso publicitario. 


\section{Publicidad y tipos de publicidad}

A partir de un análisis etimológico es posible señalar que la palabra publicidad deriva del término latín publǐcus ${ }^{1}$ que significa hacer notorio, manifiesto, patente o que pueda ser visto o sabido por todas las personas. ${ }^{2}$ Desde este enfoque, y de forma muy rudimentaria, puede decirse que la publicidad implica la realización de una acción comunicativa que persigue como fin último dar a conocer una idea u opinión respecto de algún fenómeno o hecho determinado. Pese a ello, el desarrollo que ha mostrado la práctica publicitaria hoy en día y el papel que desempeña en nuestra sociedad hacen que la anterior definición resulte insuficiente para abordarla desde un enfoque de derechos humanos.

El término publicidad, desde una perspectiva amplia, puede abarcar distintos matices y elementos no necesariamente relacionados con la venta de bienes o servicios. Así, la publicidad lato sensu puede adoptar las formas de promoción, patrocinio, relaciones públicas o publicidad comercial en sentido estricto. ${ }^{3}$

Tabla 1. Formas de publicidad lato sensu

\begin{tabular}{ll}
\hline Forma de publicidad & Descripción \\
\hline \multirow{2}{*}{ Promoción } & Es considerada como una herramienta auxiliar de \\
& la publicidad en la medida que tiene por objeto la \\
& formulación de incentivos a corto plazo que fomen- \\
& ten la compra o venta de un producto o servicio.
\end{tabular}

1 Vid. Screti, Francesco, "Publicidad y Propaganda: Terminología, Ideología, Ingenuidad" en Razón y Palabra, Primera Revista Electrónica en América Latina Especializada en Comunicación, núm 78 noviembre 2011 - enero 2012, p. 4, disponible en: <http://www.razonypalabra.org.mx/varia/N78/2a\%20parte/40_Screti_V78.pdf>.

2 Vid. Real Academia Española, Diccionario de la Lengua Española, 22a edición, "Público".

${ }^{3}$ Vega, Eugenio, "Publicidad e Imagen Global" en Fundamentos de Diseño Gráfico, Anaya Multimedia. Madrid, 1989, p. 1. 
Tabla 1. Continúa

\begin{tabular}{ll}
\hline Forma de publicidad & Descripción \\
\hline & El patrocinio se relaciona con las técnicas de rela- \\
ciones públicas en tanto lo que busca es fomentar & la creación de una buena imagen o percepción res- \\
pecto de algún producto o empresa. Sin embargo, a & diferencia de las relaciones públicas, el patrocinio se \\
& vale de la asociación de la propia imagen con even- \\
& tos cercanos que puedan contribuir a tal fin. \\
& Las relaciones públicas también constituyen una \\
& herramienta de comunicación persuasiva por me- \\
& dio de la cual se cultivan buenas relaciones con el \\
& público y se obtiene una imagen o publicidad favo- \\
& rable que repercuten necesariamente en las técnicas \\
publicitarias. & \\
Eelaciones Públicas cualquier forma pagada de presentación y pro- & moción no personal de ideas, bienes o servicios por \\
un patrocinador o empresa identificada en la socie- & dad. \\
\hline
\end{tabular}

Fuente: Elaboración propia tomando como base Kotler, Philip y Armstrong, Gary, Fundamentos del Marketing; y Labariega Villanueva, Alfonso, "El Patrocinio Publicitario: Una Nivel Figura Contractual, Una Nueva Forma de Comunicar y una Modalidad de la Estrategia de Marketing".

Ahora bien, el término publicidad ha sido objeto de diversas confusiones alimentadas por la relación u homologación que se la ha dado con otras actividades como la propaganda, así como por la actitudes reduccionistas que la han encasillado como una actividad que responde necesariamente a intereses de mercado. En este sentido, cabe señalar que el discurso publicitario constituye una herramienta que se encuentra al servicio de las diversas formas de comunicación persuasiva ${ }^{4}$ pues su utilización ha sido planteada

4 Rodríguez Centeno, Juan Carlos, "La publicidad como herramientas de las distintas modalidades de comunicación persuasiva" en Global Media fournal en Español Explorando el Mundo de la Comunicación, Instituto Tecnológico y de Estudios Superiores de Monterrey, México, volumen 1, núm. 1, primavera 2004, p. 1. 
como un vehículo ideal para llegar a la psicología de las personas y, en general de la población, con el único objetivo de persuadirlas, es decir, de generar en ellas convicciones que deriven en la elección o adquisición de un determinado objeto, servicio o idea. ${ }^{5}$ Así, O’Guinn y Tomas definen a la publicidad como todo aquel esfuerzo pagado y transmitido por medios de información que tiene por finalidad persuadir a las personas. ${ }^{6}$ De esta manera, si se considera a la publicidad como un proceso comunicativo de ideas, expresiones, hechos o descripciones que responde a fines persuasivos para que las personas se conduzcan de determinada manera, es posible que ésta pueda adoptar carices distintos que respondan a intereses diversos a los comerciales, lo que permitiría comprender que la publicidad comercial es tan sólo uno de esos matices.

Hoy en día el desarrollo de las técnicas publicitarias ha permitido que ésta amplíe su espectro de modo que ya no son únicamente las empresas quienes llevan acabo acciones publicitarias, sino que existen otros actores sociales quienes han percibido las ventajas e influencia que ofrece la publicidad y las han utilizado para dar a conocer elementos distintos a productos o servicios. En este sentido, la publicidad en nuestros días ha comenzado a alejarse de aquella perspectiva comercial para abrir paso a nuevos canales de comunicación que puedan hacer viable su extensión en otros ámbitos o esferas de la vida pública. Ello ha derivado en una clasificación amplia de la publicidad que atiende, principalmente, a los fines que se pretendan alcanzar a través del ejercicio del discurso publicitario.

5 Peña Pérez, Gloria, "Sistemas de persuasión en la comunicación publicitaria" en Olsa Moreno, Inés et. al. Actas del XXXVII Simposio Internacional de la Sociedad Española de Lingüística, Departamento de Lingüística Hispánica y Lenguas Modernas, Servicio de Publicaciones de la Universidad de Navarra, Pamplona, España, 2008, p. 651.

6 O’Guinn, Tomas, Allen, Chris y Semenik, Richard, Publicidad, International Thomson Editores, 1999, p. 6. 
Tabla 2. Tipos de publicidad

\begin{tabular}{ll}
\hline Tipo de publicidad & Contenido \\
\hline Publicidad comercial & La publicidad comercial es aquella relacionada \\
& con la actividad de venta que tiene por objeto \\
& promover o suministrar, a través de la persua- \\
& sión, de determinados bienes o servicios a las \\
& personas que integran a la sociedad. \\
& Este tipo de publicidad se encuentra estrecha- \\
& mente relacionada con los derechos de la y el \\
& consumidor en la medida en que tiene por ob- \\
& jeto que el anuncio de determinados productos \\
& o servicios no conduzcan al error publicidad en- \\
& gañosa). En este tipo de publicidad, los mensajes \\
& deben responder al principio de veracidad y con- \\
& trastación con la realidad. Asimismo, el hecho de \\
& que la publicidad informativa tenga por objeto \\
& primordial informar a las personas sobre las ca- \\
& racterísticas de determinados bienes o servicios, \\
& ello no significa que pierda su carácter persuasi- \\
& vo; por el contrario, el suministro de información \\
& constituye una técnica de persuasión que genera \\
& certeza y seguridad al adquirir un producto o \\
& servicio. \\
& Este tipo de publicidad también es de carácter \\
& persuasivo, y al igual que la mayoría de la pu- \\
& blicidad, es pagada, interesada e intencionada. \\
& Sin embargo, a diferencia de los otros tipos de \\
& publicidad, ésta responde a causas concretas y a \\
& intereses sociales lo cual la aleja de la concepción \\
& comercial tradicional. Asimismo, la publicidad \\
& social pretende tener efectos que contribuyan \\
& al desarrollo o mejoramiento social y humano a \\
& través de programas de cambio y de acciones de \\
& concienciación y sensibilización social. \\
Publicidad social &
\end{tabular}


Tabla 2. Continúa

\begin{tabular}{ll}
\hline Tipo de publicidad & Contenido \\
\hline & $\begin{array}{l}\text { La publicidad legal u oficial se diferencia del } \\
\text { resto de los tipos de publicidad en virtud de la } \\
\text { obligatoriedad en la difusión de mensajes ob- }\end{array}$ \\
jetivos. Este tipo de publicidad hace posible la \\
Publicidad legal u oficial \\
realización de algunos derechos y característi- \\
cas que distinguen a un gobierno democrático \\
tales como la transparencia, la rendición de \\
cuentas y el acceso a la información. \\
Este tipo de publicidad constituye una forma de \\
comunicación informativa y a la vez persuasiva \\
que tiene por objeto dar a conocer a las y los ciu- \\
dadanos el funcionamiento y los procedimientos \\
correspondientes del servicio público de carácter \\
jurídico, electoral, laboral, económico o cultural.
\end{tabular}

Fuente: Elaboración propia tomando como base Martínez Pastor, Esther, "La Publicidad ¿Derecho Fundamental o de Empresa? Una perspectiva jurídico informática”.

\section{Discurso público y DISCURSO COMERCIAL}

En líneas anteriores se ha analizado a la publicidad a partir de su naturaleza propia, así como de los fines que ésta persigue. Ahora, es importante centrar su estudio desde un enfoque jurídico que permita determinar si el ejercicio de la publicidad comercial puede ser susceptible de protección a través del marco normativo del Estado.

El ámbito jurídico ha distinguido dos principales tipos de discursos a los cuales les ha asignado características propias y niveles de aseguramiento diferenciados; por una parte, es posible identificar al discurso público y por la otra al discurso comercial. En torno a ello, ha sido la Corte Suprema de los Estados Unidos de América (CSEUA) quien a través de su jurisprudencia ha desarrollado, en mayor medida, las características del discurso público frente al discurso comercial a través de la doctrina conocida como commercial 
speech. Esta doctrina permitió a las autoridades judiciales estadounidenses determinar si el discurso comercial entraba bajo la protección de la Primera Enmienda de la Constitución de aquel país ${ }^{7}$ y clarificar el alcance de las restricciones de dicho discurso. Al final, para la Corte Suprema de Estados Unidos el discurso público es aquél que permite la transmisión de ideas y expresiones capaces de contribuir al desarrollo de debates de interés general y que sean de utilidad para la sociedad en su conjunto, por lo que cualquier restricción que se intente establecer a la difusión de ideas en el marco del discurso público, deberán ser analizadas bajo un test de escrutinio estricto de proporcionalidad. ${ }^{8}$

En relación con el discurso publicitario o commercial speech, la Corte Suprema norteamericana señaló en un primer momento que éste se constituye por la expresión de ideas relacionadas con los intereses económicos del anunciante y su audiencia, así como por la promoción de transacciones de naturaleza estrictamente comercial; ${ }^{9}$ no obstante, esta definición pronto tuvo que ser repensada en virtud de las distintas formas en las cuales el discurso comercial puede materializarse. Por ejemplo, el mencionado tribunal en el caso Virginia State Board of Pharmacy señaló que el commercial speech se encuadraba en la protección otorgada por la Primera Enmienda

7 La primera enmienda a la Constitución de los Estados Unidos de Norteamérica señala: "El Congreso no hará ley alguna por la que adopte una religión como oficial del Estado o se prohiba practicarla libremente, o que coarte la libertad de palabra o de imprenta, o el derecho del pueblo para reunirse pacificamente y para pedir al gobierno la reparación de agravios." Cfr. Constitución de los Estados Unidos de América de 1787 disponible en: <http:// www.archives.gov/espanol/constitucion.html>.

8 Sukhatme, Neel U., "Making Sense of Hybrid Speech: A New Model for Commercial Speech and Expressive Conduct" en Harvard Law Review, Vol. 118, 2205, pp. $2836-2840$.

9 Vid. Valeryevna Gassy-Wright, Oxana, "Commercial Speech in the United States and Europe", en Georgia Law, Digital Commons @ Georgia Law, LLM Theses and Essays, University of Georgia School of Law, 2005, p. 15. Asimismo, vid. Corte Suprema de los Estados Unidos de América (CSEUA), Central Hudson Gas \& Electric Corp v. Public Services Comission, 447 U.S 557, 20 de junio de 1980. 
toda vez que su vinculación con el mercado de bienes y servicios no necesariamente lo alejaba del mercado de las ideas; además determinó que el carácter pagado de la publicidad no constituye un argumento suficientemente válido para sustraerla de la protección constitucional que requiere la libre manifestación y expresión de ideas ajenas. ${ }^{10}$ Así, la sentencia en cuestión estableció la relación e importancia que existe entre el discurso comercial y el interés general de la sociedad al afirmar que:

El particular interés de los consumidores en el libre flujo de información comercial, puede ser tan agudo, sino es que me mucho más agudo, que el interés que puedan tener en el debate político más urgente del día. [...]De manera general, la sociedad también puede presentar un fuerte interés en el libre flujo de información comercial. Incluso, un mensaje publicitario estrictamente comercial, puede ser de interés público general. ${ }^{11}$

En similar sentido, en un asunto relacionado con la regulación de publicidad en materia de bebidas alcohólicas, el tribunal constitucional norteamericano señaló que: "Las prohibiciones al discurso comercial no sólo dificultan las decisiones de los consumidores, sino que también impiden el debate respecto de asuntos fundamentales de política pública." 12

Esta distinción entre discurso público y discurso comercial condujo a que la Corte Suprema de Estados Unidos adoptara niveles de

10 Vid. CSEUA, Virginia State Board of Pharmacy v. Virginia Citizens Consumer Council, Inc., 425 U.S 748, 24 de mayo de 1976.

11 CSEUA, Virginia State Board of Pharmacy, op. cit., "As to the particular consumer's interest in the free flow of commercial information, that interest may be as keen, if not keener by far, than his interest in the day's most urgent political debate [...] Generalizing, society also may have a strong interest in the free flow of commercial information. Even an individual advertisement, though entirely 'commercial' may be of general public interest", traducción propia del autor.

12 CSEUA, 44 Liquormart Inc. v. Rhode Island, 517 U.S. 484, 13 de mayo de 1996, "In this way, these commercial speech bans not only hinder consumer choice, but also impede debate over central issues of public policy", traducción propia del autor. 
protección diferenciados respecto de cada uno de ellos. Por ejemplo, en materia de discurso comercial, el tribunal constitucional estadounidense ha señalado que si bien dicho discurso goza de la protección que otorga la Primera Enmienda, ello no quiere decir que toda clase de anuncio publicitario tenga que ser protegido ${ }^{13}$ sino que aquellos mensajes publicitarios que conlleven un riesgo de engaño o coerción no podrán ser beneficiados de la garantía y protección constitucionales. ${ }^{14}$ De manera similar en México, la Suprema Corte de Justicia de la Nación (SCJN) ha hecho suyos los criterios desarrollados por el tribunal estadounidense y ha colocado a la publicidad comercial en un nivel inferior de protección señalando que ésta apoya al ejercicio de la una libertad empresarial y por ende se circunscribe únicamente a proponer la realización de transacciones comerciales, por lo que su producción puede quedar sujeta a una regulación dentro de límites mucho más amplios en los que le sean exigidos requisitos de veracidad y claridad. ${ }^{15}$

A fin de delimitar los casos en los cuales el discurso publicitario puede ser restringido sin que ello se torne en una vulneración a derechos fundamentales, la CSEUA formuló un test basado en cuatro elementos principales que permiten determinar la validez de una restricción; ${ }^{16}$ dicho test ha recibido el nombre de Central Hudson test (en virtud del caso que le dio origen $)^{17}$ y también es conocido como four prong test.

13 C.SEUA, Central Hudson Gas Ë Electric Corp., op. cit.
14 C.SEUA, Ohralik v. Ohio State Bar Assn., 436 U.S. 447, 30 de mayo de 1978.
15 Vid. SGJN, [TA]; 9a. Época; la. Sala; S.J.F. y su Gaceta; XXI, Enero de 2005; p. 421, "Libertad de expresión e imprenta. Las limitaciones establecidas por el legislador relacionadas con la veracidad y claridad de la publicidad comercial son constitucionales cuando incidan en su dimensión puramente informativa".

16 M. Garon, Jon, "Beyond the First Amendment: Shaping the Contours of Commercial Speech in Video Games, Virtual Worlds and Social Media”, en $N K U$ Chase Law E Informatic Institute, Working Paper Series, Northern Kentucky University, 2011 , p. 5.

17 C.SEUA, Central Hudson Gas E Electric Corp., op. cit. 
El Central Hudson Test señala que para que el discurso comercial pueda ser restringido es necesario que: ${ }^{18}$

1. El discurso comercial se encuentre protegido, es decir, que refiera a una actividad lícita y que el mismo no sea engañoso;

2. El interés gubernamental o del Estado respecto de la limitación del discurso sea sustancial;

3. La regulación del discurso comercial se relacione directamente con el interés gubernamental perseguido;

4. La limitación o regulación no supere a aquélla que sea esencial para la consecución del interés perseguido.

Si bien el test antes referido ha constituido la base sobre la que las autoridades judiciales norteamericanas han resuelto muchos casos relacionados con el discurso comercial, es importante apuntar que dicho test se torna gris al momento de analizar mensajes publicitarios que traen aparejados al mismo tiempo elementos característicos del discurso público y del discurso comercial. El tribunal supremo de Estados Unidos no ha sentado un criterio claro respecto a discursos de naturaleza mixta; en todo caso, el asunto que más se aproxima a esta problemática es del Bolger vs. Young Drug Products en el cual la Corte Suprema determinó que el envío de folletos que promocionaban una marca de condones, y que a su vez informaban de la utilidad y ventajas que dichos anticonceptivos ofrecían en torno a infecciones de transmisión sexual, constituían el ejercicio de un discurso comercial que se encontraba protegido a la luz de la doctrina del commercial speech. Asimismo, señaló que la medida restrictiva que la Oficina Postal de Columbia pretendía establecer no era proporcional a los fines que el gobierno perseguía. ${ }^{19}$

En este contexto, el fenómeno de los discursos mixtos, es decir, aquéllos en los que resulta poco clara la distinción entre lo público

18 Idem.

19 C.SEUA, Bolger v. Youngs Drug Products Corp., 463 U.S. 60, 24 de junio de 1983. 
y lo comercial, ha llamado la atención y ha constituido la base sobre la que se analizan los alcances y límites del discurso publicitario. Esta situación ha sido propicia para formular una clasificación respecto de los discursos de naturaleza mixta.

Tabla 3. Discursos de naturaleza mixta

\begin{tabular}{|c|c|}
\hline Discurso & Características \\
\hline $\begin{array}{l}\text { Discursos públicos } \\
\text { con efecto publicitario } \\
\text { residual }\end{array}$ & $\begin{array}{l}\text { Este tipo de discurso se integra a través de men- } \\
\text { sajes que pueden contribuir al desarrollo y for- } \\
\text { talecimiento de la opinión pública, pero que al } \\
\text { mismo tiempo generan un efecto publicitario en } \\
\text { menor medida para las personas receptoras de } \\
\text { dichos mensajes. }\end{array}$ \\
\hline $\begin{array}{l}\text { Comunicaciones } \\
\text { comerciales que } \\
\text { contribuyen de forma } \\
\text { residual al discurso } \\
\text { público }\end{array}$ & $\begin{array}{l}\text { A diferencia del caso anterior, este discurso se } \\
\text { conforma por comunicaciones motivadas princi- } \\
\text { palmente por razones publicitarias y económicas } \\
\text { pero que impactan de manera menos gradual } \\
\text { en el desarrollo de ideas u opiniones de interés } \\
\text { general que contribuyen al desarrollo del debate } \\
\text { público. }\end{array}$ \\
\hline $\begin{array}{l}\text { Discursos públicos } \\
\text { con incidencia en el } \\
\text { mercado }\end{array}$ & $\begin{array}{l}\text { En este caso, el discurso es desarrollado por un } \\
\text { sujeto ajeno al mundo del comercio, pero cuya } \\
\text { expresión de ideas impacta necesariamente en la } \\
\text { configuración y dinámica del mercado. }\end{array}$ \\
\hline $\begin{array}{l}\text { Discursos públicos } \\
\text { que utilizan formas de } \\
\text { expresión propias del } \\
\text { discurso comercial }\end{array}$ & $\begin{array}{l}\text { Este discurso tiene la clara intención de promo- } \\
\text { ver el desarrollo de ideas que alimenten al deba- } \\
\text { te público dentro de la sociedad. Para ello, este } \\
\text { discurso utiliza los mecanismos y características } \\
\text { propias del discurso comercial de modo que su } \\
\text { ejercicio puede o no impactar en la dinámica del } \\
\text { comercio. }\end{array}$ \\
\hline
\end{tabular}

Fuente: Elaboración propia tomando como base Rubí I Puig, Antonio, Publicidad Comercial y Libertad de Expresión. La Protección Constitucional de la Información en el Mercado. 
La utilización cada vez más constante de la publicidad comercial y su interrelación con temas ya no únicamente de carácter empresarial ha conducido a la dificultad de distinguir entre el discurso de lo público y lo privado, pues plantea un escenario en el que la manifestación y recepción de ideas se relaciona ya no sólo con actividades comerciales sino con el ejercicio de ciertos derechos humanos que contribuyen al fortalecimiento y consolidación de sociedades democráticas y plurales, así como a la construcción de una opinión pública libre e informada.

III. LA PUBLICIDAd COMERCIAL COMO EJERCICIO DEL DERECHO A LA LIBERTAD DE EXPRESIÓN

El derecho a la libertad de expresión constituye un derecho fundamental reconocido en la mayoría de los instrumentos internacionales en materia de derechos humanos. ${ }^{20}$ En sentido estricto, este derecho implica la posibilidad de toda persona de manifestar y expresar libremente sus ideas u opiniones a través de cualquier medio, ya sea oral, escrito, artístico o impreso. ${ }^{21}$

20 ONU, Declaración Universal de los Derechos Humanos (DUDH), aprobada por la Asamblea General de las Naciones Unidas en su resolución A/RES/3/217 durante su III periodo de sesiones el 10 de diciembre de 1948, artículo 19; ONU, Pacto Internacional de Derechos Civiles y Políticos (PIDCP), aprobado por la Asamblea General de las Naciones Unidas en su resolución A/RES/2200 durante su XXI periodo de sesiones, New York, 16 de diciembre de 1966, artículo 19; CE, Convenio Europeo para la Protección de los Derechos Humanos y de las Libertades Fundamentales (CEDH), aprobado por el Consejo de Europa, Roma, 1950, artículo 10; OEA, Convención Americana sobre Derechos Humanos (CADH), suscrita en la Conferencia Especializada Interamericana sobre Derechos Humanos, San José, Costa Rica, 7 al 22 de noviembre de 1969, artículo 13; ouA, Carta Africana sobre los Derechos Humanos $y$ de los Pueblos "Carta de Banjul" (CADHP), aprobada por la XVIII Asamblea de Jefes de Estado y Gobierno de la Organización de la Unidad Africana, Nairobi, Kenia, 27 de julio de 1981, artículo 9.

21 Vid., OEA, Convención Americana sobre Derechos Humanos, op. cit., artículo 13, vid. Corte IDH, Caso Herrera Ulloa v. Costa Rica, Excepciones Preliminares, Fondo 
Respecto de la libertad de expresión, la Corte Interamericana de Derechos Humanos (CORTE IDH) ha sostenido que este derecho se integra por dos vertientes: una de carácter individual y otra de naturaleza colectiva. ${ }^{22}$ En relación con la primera vertiente, dicho tribunal ha señalado que se conforma por la posibilidad que tiene todo ser humano de manifestar sus ideas o pensamientos ${ }^{23}$ de manera libre y hacerlas llegar al mayor número de destinatarios ${ }^{24}$ por lo que el Estado debe asegurar los medios necesarios para tal efecto y evitar el establecimiento de restricciones arbitrarias o injustificadas que coarten el ejercicio de dicho derecho. Por su parte, la vertiente colectiva del derecho a la libertad de expresión implica la posibilidad que tienen todas las personas dentro de la sociedad de recibir y beneficiarse del pensamiento y las expresiones ajenas. ${ }^{25}$

El ejercicio del derecho a la libertad de expresión, en términos del artículo 13 de la CADH, puede materializarse a través de distintos medios ya sean éstos de naturaleza escrita, oral, artística o cultural, por lo que adoptando una interpretación extensiva de dicho precepto convencional es posible afirmar que el discurso comercial y los anuncios publicitarios pueden integrarse a la lista de

y Reparaciones y Costas, Sentencia de 2 de julio de 2004, , Serie C. No. 107, p. 65, párr. 108 .

22 Corte IDH, Caso López Álvarez v. Honduras, Fondo, Reparaciones y Costas, Sentencia de 1 de febrero de 2006, Serie C No. 141. párr. 163.

23 Andreu Martínez, María Belén, "La Libertad de Expresión y los Derechos al Honor e Intimidad en la Jurisprudencia Española y el Tribunal Europeo de Derechos Humanos" en Memorias del Seminario Internacional "Los Derechos Humanos y la Libertad de Expresión en México", Programa de Cooperación sobre Derechos Humanos México - Comisión Europea, Secretaría de Relaciones Exteriores, 2006, p. 151 .

24 Corte IDH, Caso "La Última Tentación de Cristo" (Olmedo Bustos y otros) v. Chile, Fondo, Reparaciones y Costas, Sentencia de 5 de febrero de 2001, Serie C No. 73, párr. 65.

25 Corte IDH, La Colegiación Obligatoria de Periodistas (Arts. 13 y 29 Convención Americana sobre Derechos Humanos), Opinión Consultiva OC-5/85 del 13 de noviembre de 1985. Serie A No. 5, p. 70. 
vehículos que permiten la manifestación de ideas, toda vez que son las limitaciones, y no las posibilidades al ejercicio de un derecho las que deben analizarse de manera restrictiva. ${ }^{26}$ De este modo, la transmisión de anuncios publicitarios puede encuadrarse en el ejercicio del derecho a la libertad de expresión en las dos vertientes que integran a este derecho. Por una parte, y desde la óptica individual, es factible señalar que son las empresas, los anunciantes y los medios de comunicación quienes tienen la posibilidad de manifestar sus ideas a través de dichos anuncios publicitarios; mientras que desde el enfoque colectivo, es la sociedad y las personas que la integran, quienes cuentan con el derecho de recibir aquellas ideas, manifestaciones y expresiones publicitarias que les permitirán tomar decisiones informadas y que contribuirán al fomento de prácticas competitivas en el mercado, que redundarán en su beneficio, así como en el de las empresas publicitarias.

En relación con lo anterior, si bien la publicidad comercial tiene como finalidad persuadir a las personas para adquirir un determinado bien o servicio, no en todos los casos su impacto se reduce a la manifestación o promoción de elementos materiales; por el contrario, es importante tomar en consideración que la realización y difusión de anuncios publicitarios, antes que otra cosa, constituye un mecanismo de utilidad para la transmisión de ideas o comunicaciones que sirven de apoyo para la adopción de decisiones informadas dentro de la dinámica social y comercial. ${ }^{27}$ Esta situación se torna mucho más clara si se toma en consideración que hoy en día distintas empresas han utilizado las vías publicitarias para transmitir y potencializar ideas y valores relacionados con el público al que van

26 Gorrotxategi, Mirem, "Publicidad y libertad comercial Algunas reflexiones tras la sentencia del caso Benetton en Alemania" en Questiones Publicitarias Revista Internacional de Comunicación y Publicidad, Vol. 1, núm. 5, 1996, p. 110.

27 Gil Membrado, Cristina, "El Anuncio Publicitario como Ejercicio del Derecho a la Libre Expresión. A Propósito del Caso Mitsubishi” en InDret Revista para el Análisis del Derecho, Universitat de les Illes Balears, Barcelona, 2011, p. 6. 
dirigidos los mensajes publicitarios y los cuales no siempre se encuentran relacionados con el producto o servicio que publicitan. ${ }^{28}$

En este sentido, el Tribunal Constitucional Federal Alemán ha establecido que la práctica relativa a la transmisión de anuncios publicitarios queda protegida por el derecho a la libertad de expresión cuando éstos difunden juicios de valor o manifiestan ideas que promueven la formación de opinión pública. ${ }^{29}$ Por su parte, la Corte Constitucional de Colombia ha tenido la oportunidad de pronunciarse sobre este tema al señalar que el derecho a la libertad de expresión se vulnera cuando se priva a las personas de acudir, legítimamente, a los mecanismos publicitarios para dar a conocer las cualidades de aquellos productos que anuncian. ${ }^{30}$ Estas decisiones son un claro ejemplo de la evolución que ha presentado tanto el análisis como la regulación normativa de la publicidad comercial en distintos países del mundo y contribuyen a distanciar el discurso publicitario de aquella visión reduccionista que lo consideraba únicamente al servicio de intereses de empresa, comenzando a ubicarlo en un plano de protección constitucional desde la perspectiva de los derechos humanos.

Pese a lo anterior, ni la libertad de expresión, ni cualquier otro derecho pueden ser considerados como valores o prerrogativas de carácter absoluto, sino que en algunas ocasiones su ejercicio puede verse sometido a limitaciones para garantizar el goce y ejercicio de otros derechos humanos, siempre que dichas limitaciones se encuentren orientadas por razones de legalidad, necesidad, propor-

28 Pardo, M. et. al., "Libertad, Igualdad, Publicidad" en Derecho Constitucional III, Universidad de Murcia, España, p. 12. Asimismo, es importante mencionar que dicho criterio también ha sido sostenido por la Corte Suprema de Estados Unidos y la Corte Constitucional de Colombia.

29 Vid. Rubí r Puig, Antonio, Publicidad Comercial y Libertad de Expresión. La Protección Constitucional de la Información en el Mercado, Tesis Doctoral, Universidad Pompeu Fabra, 2007 haciendo referencia a la sentencia del Tribunal Federal Constitucional Alemán BVerfGE 71/162 del 19 de noviembre de 1985.

зо Vid. Corte Constitucional de Colombia, Sentencia T-381 de 1994. 
cionalidad e idoneidad. ${ }^{31}$ Por lo que toca a la publicidad comercial analizada desde el enfoque de la libertad de expresión, es necesario señalar que su ejercicio puede ser objeto de restricciones cuando su contenido resulte contrario a los derechos o a la dignidad de otras personas, así como cuando incite o promueva al odio y a la violencia. Al respecto, el Relator Especial de Naciones Unidas para la Libertad de Expresión se ha pronunciado sobre la existencia de cuatro tipos de expresión que los Estados deben prohibir en cumplimiento de los principios y obligaciones que rigen al derecho internacional de los derechos humanos, a saber: 1) la pornografía infantil; 2) la incitación pública y directa del genocidio; 3) el odio nacional, racial o religioso que promueva discriminación, hostilidad y violencia; y 4) la incitación al terrorismo. ${ }^{32}$

Desde esta perspectiva, las limitaciones al ejercicio de la publicidad comercial deben establecerse únicamente cuando a través de ella se expresen o difundan ideas contrarias a los valores que persigue una sociedad democrática y respetuosa de los derechos humanos, por lo que la consideración aislada de su carácter comercial no puede constituir una causa justificada para su limitación, sino que en todo caso deberá realizarse un examen de proporcionalidad que le otorgue legitimidad. Aunado a ello, el discurso publicitario comercial no únicamente se encuentra sujeto a restricciones que derivan del derecho a la libertad de expresión, pues su relación material con otros derechos, así como su influencia y alcance dentro de la sociedad hacen necesario el establecimiento de mecanismos

31 Alexy, Robert, Teoría de los Derechos Fundamentales, Centro de Estudios Constitucionales, Madrid, España, 1993, pp. 111 a 115. Asimismo, vid. Corte IDH, Caso Kimel vs. Argentina, Fondo, Reparaciones y Costas, Sentencia de 2 de mayo de 2008 Serie C No. 177, párrs. 56, 70, 74 y 83.

32 ONU, Promotion and protecticon of the right to freedom of opinion and expression. Report of the Special Rappourter on the Promotion and Protection of the right to freedom of opinion and expression, sometido a la Asamblea General de las Naciones Unidas en resolución A/66/290 durante su LXVI periodo de sesiones, New York, 10 agosto de 2011 , pp. 8 a 12. 
adicionales de regulación para garantizar que su impacto sea, en todo caso, positivo.

IV. LA PUBLICIDAd COMERCIAL EN EL MARCO DEL DERECHO A LA INFORMACIÓN

La publicidad comercial también presenta una estrecha relación con el derecho a la información, el cual es entendido como la posibilidad que tienen todas las personas para buscar, emitir y recibir cualquier tipo de informaciones y, al igual que el derecho a la libertad de expresión, presenta una vertiente individual y una colectiva. ${ }^{33} \mathrm{~A}$ diferencia del contenido de los mensajes o ideas que se transmiten a través del ejercicio del derecho a la libertad de expresión los cuales pueden constituir juicios de valor u opiniones; en el caso del derecho a la información es necesario que todos los datos que se transmitan cumplan con los requisitos de veracidad e interés general, es decir, que puedan ser objetivamente contrastables con la realidad. ${ }^{34}$

En relación con la publicidad comercial, es necesario considerar que dicha práctica, además de servir a intereses persuasivos económicos y de transmitir ideas o valores en algunos casos, también expresa información relacionada con los productos o servicios que promocionan y que serán adquiridos por las y los espectadores que reciban dichos mensajes. En particular, el hecho de que la publicidad comercial, en algunas ocasiones, proyecte anuncios publicita-

33 Corte IDH, Caso Claude Reyes y otros vs. Chile, Fondo, Reparaciones y Costas, Sentencia de 19 de septiembre de 2006, Serie G núm. 151, párr. 77.

34 Vid., Tribunal Supremo Español, Sentencia del 22 de julio de 2011 dictada por la Sala Primera del Tribunal Supremo al recurso de casación No. 1089/2009, Madrid, España. p. 4. Asimismo, vid. SCJN, [TA]; 9a. Época; 1a. Sala; S.J.F. y su Gaceta; XXX, Diciembre de 2009; p. 284; "Libertad de expresión y derecho a la información. Modo en que deben ser entendidos los requisitos de veracidad e imparcialidad"; y SCJN, [TA]; 9a. Época; T.C.C.; S.J.F. y su Gaceta; XXV, Marzo de 2007; p. 1779; "Responsabilidad de periodistas y medios de comunicación. Concepto de veracidad". 
rios que pudieran parecer triviales o sin sentido, no significa que los datos que transmitan no puedan ser de utilidad para las personas al momento de tomar una determinada decisión respecto al producto o servicio que se promociona, toda vez que dicho mensaje puede incluir información relacionada con el producto, sus características, su utilidad y su precio, así como con el vendedor y la imagen que éste proyecte a la sociedad. ${ }^{35}$

El hecho de que la publicidad comercial, al momento de promocionar un producto, tenga que verse sometida a los requisitos de veracidad e interés general que revisten a la información, constituye un elemento de valiosa importancia en lo que se refiere a los derechos de las y los consumidores ${ }^{36}$ en virtud de que lo se persigue es, en realidad, salvaguardar que éstas y éstos no sean inducidos al engaño o al error a través de anuncios publicitarios, también denominados publicidad engañosa. ${ }^{37}$ Dicho requisito de veracidad en materia de publicidad comercial no necesariamente constituye un freno al alcance persuasivo que ésta conlleva, es decir, información y persuasión no son precisamente términos contradictorios, pues persuadir no significa engañar. Por el contrario, el hecho de que la

35 CSEUA, Virginia State Board of Pharmacy, op. cit., traducción propia del autor.

36 CSEUA, Central Hudson Gas \& Electric Corp., op. cit.

37 La publicidad engañosa es aquélla cuya presentación induce o puede inducir al error en los destinatarios y afectar su comportamiento económico. Este tipo de publicidad también se caracteriza por generar un perjuicio a los demás competidores económicos. Vid. Acuña Ledesma, María Lourdes, "Nuevas Formas de Publicidad en el Siglo XXI: El Problema de la Publicidad Engañosa" en Derecom Revista Especializada en Derecho a la Comunicación, núm 8, Nueva Época, Diciembre - Febrero 2012, Asimismo, vid. Martínez Pastor, Esther, "La Publicidad ¿Derecho Fundamental o de Empresa? Una perspectiva jurídico informática” en Derecom Revista Especializada en Derecho a la Comunicación, núm 8, Nueva Época, Diciembre - Febrero 2012. De igual forma, la legislación mexicana considera como engañosa a toda aquella publicidad que sea falsa, inexacta, exagerada, parcial y/o artificiosa o tendenciosa, vid., PRofeco, Acuerdo por el que se establecen los lineamientos para el análisis y verificación de la información y publicidad, publicado en el DOF el 24 de julio de 2012. 
publicidad comercial pueda ofrecer información veraz y objetiva sobre los productos y servicios que promociona posibilita una interacción más fluida y libre en beneficio de las distintas empresas competidoras y de la sociedad en su conjunto.

En este punto, considerar que la publicidad comercial puede estar sujeta a determinadas restricciones a la luz de los derechos a la libertad de expresión y de información, conduce, necesariamente, al análisis respecto de la regulación y papel que los medios de comunicación masiva deben asumir en el marco de una sociedad libre, democrática y plural comprometida con el reconocimiento y aseguramiento de las condiciones y características particulares de cada grupo que la integran.

\section{Publicidad COMERCIAL Y MEdios DE COMUNICACIÓN MASIVA: MECANISMOS DE REGULACIÓN Y AUTORREGULACIÓN}

Los medios de comunicación masiva (MCM) y la publicidad de las empresas que en ellos se transmiten han cobrado total relevancia en el ámbito de lo social debido al creciente acceso a las tecnologías de información y comunicación, lo que permite que un mayor número de personas reciban dicha información. ${ }^{38}$ Debido a este importante

38 De acuerdo con un estudio Digital TV World Household Forecast realizado en 73 países y publicado por Digital TV Research, el número de hogares con televisión digital se duplicará entre el año 2010 y 2016 alcanzando una cifra de 1, 189 millones. Dicho informe estima que la penetración digital en el ámbito de la TV pasará de un 42.5\% de finales del 2010 a un 80\% en el año 2016. En el caso de México si bien la transición a la televisión digital comenzó hasta hace poco tiempo, de acuerdo con datos de la Encuesta Nacional sobre disponibilidad y uso de tecnología de información y comunicación en los hogares 2010 elaborada por el Instituto Nacional de Estadística y Geografía (INEGI), el 86.1\% de la población mexicana cuenta con un televisor analógico y 13.9\% con uno de carácter digital. Del mismo modo, de conformidad con el documento "Avances en el acceso y el uso de las Tecnologías de la Información y la Comunicación en América Latina y el Caribe 2008 - 2010" publicado por la Comisión Económica para América y el Caribe (CEPAL), durante los últimos cinco años, la cantidad de usuarios de Internet ha crecido sustancialmente, pasan- 
crecimiento, resulta necesario redefinir y redireccionar el papel que la publicidad y los MCM desempeñan actualmente en la sociedad y en la construcción de ideas, valores y criterios, ${ }^{39}$ pues tal como lo ha sostenido la SCJN, "los medios de comunicación social se cuentan entre los forjadores básicos de la opinión pública en las democracias actuales y es indispensable que tengan aseguradas las condiciones para incorporar y difundir las más diversas informaciones y opiniones". ${ }^{40}$ En primer lugar, y como ha sido sostenido, es necesario sobreponerse a la idea de que la publicidad únicamente persigue fines comerciales o de lucro, sino que debe plantearse la posibilidad de utilizar a la publicidad como mecanismo de promoción y educación aprovechando su fuerza, alcance e impacto para crear una sociedad respetuosa y garante de derechos humanos.

Es así que, debido a la evolución que la publicidad ha desarrollado a lo largo de los años, se ha abierto paso al concepto denominado publicidad social, el cual, como ha sido referido anteriormente, considera a las prácticas publicitarias como un agente de cambio en la medida en que enfocan sus actividades, mensajes e ideas a lograr un cambio en la construcción y divulgación de valores, a través de la adopción o el abandono de determinados patrones de conducta para beneficio de la misma sociedad. ${ }^{41}$ Asimismo, el surgimiento de este concepto ha permitido que la práctica dirigida a la transmisión de mensajes pagados a través de MCM se haga extensiva a otro tipo de organizaciones o sujetos que no necesariamente persiguen un

do de una tasa de 11\% de penetración en 2003 a 27\% en 2008. Actualmente en México el 22\% de los hogares cuenta con una computadora con acceso a Internet.

39 Vid. SCJN, [TA]; 10a. Época; 1a. Sala; S.J.F. y su Gaceta; Libro IV, Enero de 2012, Tomo 3; p. 2914; "Medios de comunicación. Su consideración como figuras públicas a efectos del análisis de los límites a la libertad de expresión".

40 Vid. SCJN, [TA]; 9a. Época; 1a. Sala; S.J.F. y su Gaceta; XXX, Diciembre de 2009; p. 288; "Libertades de expresión e información. Los medios de comunicación de masas juegan un papel esencial en el despliegue de su función colectiva".

41 Vid. Kotler, Philip y Roberto, Eduardo L., Marketing social. Estrategias para cambiar la conducta pública, Ed. Díaz de Santos, Madrid, 1992. 
fin de lucro, como lo son las organizaciones no gubernamentales, partidos políticos, sindicatos, organismos públicos de protección a derechos humanos, entre otros. ${ }^{42}$

La conjugación entre publicidad social y publicidad comercial permite comprender que la construcción de una sociedad responsable y comprometida con el respeto y garantía de los derechos humanos no es necesariamente contraria al carácter comercial que puedan perseguir determinadas empresas debido a que aquéllas que tienen por objeto principal la venta de productos o servicios pueden incluir en sus anuncios publicitarios cierto tipo de mensajes que promuevan en las y los espectadores una idea positiva de respeto hacia los demás, hacia la comunidad o hacia el medio ambiente y, al mismo tiempo, alcanzar un beneficio particular. Con todo y ello, la regulación respecto a la transmisión de mensajes publicitarios en MCM es un tema que requiere de especial consideración, sobre todo en lo que se refiere al equilibrio de obligaciones y compromisos que deben asumir tanto el Estado como las empresas privadas de comunicaciones.

\section{Autorregulación y Responsabilidad social de las EMPRESAS Y MCM EN EL ÁMBITO DE LA PUBLICIDAD COMERCIAL}

Es necesario admitir que no todas las empresas incorporan como uno de sus objetivos el desarrollo e implementación de un contenido social en los mensajes publicitarios que transmiten a través de los MCM. Sin embargo, esta situación no puede constituir un obstáculo para que las empresas realicen prácticas publicitarias que

42 En este sentido, el papel que juegan, especialmente, las ONG y los organismos públicos de protección a los derechos humanos resultan de total importancia en la medida en que no sólo exponen y transmiten el contenido y alcance de determinados derechos, sino que permiten transmitir, a su vez a la sociedad, la existencia de entidades dedicadas a la protección y defensa de las personas que crean haber sido víctimas de violación a sus derechos humanos lo que podría traducirse en un mecanismo de acceso a la justicia. 
atenten contra la sociedad y sus integrantes o contra los valores que permitan una convivencia armónica y respetuosa de las personas y sus derechos; pues tanto MCM como empresas, a través del ejercicio de la publicidad, tienen un compromiso importante hacia con la comunidad. En primer lugar debido a que se encuentran en una posición privilegiada al ser capaces de transmitir mensajes que serán recibidos por la sociedad y, en segundo lugar, debido a que dicho grupo será el que adquiera los productos o servicios promovidos a través de los medios ya referidos.

En este sentido, la Corte Constitucional Colombiana se ha pronunciado sobre la responsabilidad social de los MCM al señalar que ésta se orienta:

[...] en primer término al compromiso con los ideales democráticos, adquiriendo un sentido la libertad transmitida en ellos, no de prevalencia de intereses personales o de grupo sino, principalmente colectiva. Los medios impresos, radiales o televisivos, disponen de una capacidad no sólo para defender determinadas posiciones, sino que éstas deben encuadrarse en el marco del interés general para no convertir el poder de que disponen en agente de privilegios contrarios al pluralismo que se busca realizar. ${ }^{43}$

La responsabilidad social de las empresas -también denominada responsabilidad social corporativa (RSG) - constituye un elemento de política institucional que ha sido adoptado con mayor frecuencia por múltiples empresas durante los últimos años. Al respecto, la RSC puede definirse como el conjunto de principios, acciones, políticas y programas encaminados hacia el respeto al entorno social y natural por medio de las cuales las empresas se hacen responsables de los impactos que sus actividades generan en los distintos ámbitos de la vida social. La RSC parte de un suelo mínimo establecido por la legislación internacional en materia laboral, social y de derechos humanos y alcanza su culminación o grado máximo de optimiza-

43 Vid. Corte Constitucional de Colombia, Sentencia T048/93. Santafé de Bogotá, D.C., febrero quince (15) de mil novecientos noventa y tres (1993). 
ción en los límites y metas que cada empresa desee alcanzar en el desarrollo de actividades empresariales responsables. ${ }^{44}$ Así, este concepto puede hacerse extensivo a las empresas que realizan prácticas publicitarias a través de MCM, lo cual puede traducirse en el establecimiento de principios que permitan regir la actividad de los anunciantes tomando como base el compromiso hacia el respeto de los derechos y valores características de una sociedad y de sus integrantes.

La materialización de la RSC hace necesaria la adopción e implementación de ordenamientos que contengan reglas y principios básicos que permitan a los anunciantes autorregular su actuación e impacto publicitario en la comunidad. Ejemplo de ello lo constituye la existencia de diversos códigos de ética adoptados por organizaciones de autorregulación publicitaria de distintos países latinoamericanos. ${ }^{45}$ Dichos ordenamientos, si bien no poseen un carácter vinculante, sí expresan, al menos, un compromiso por parte de las empresas de incidir de manera positiva en la audiencia receptora de sus mensajes aunque en realidad es justamente su carácter programático uno de los puntos más flacos de este tipo de autorregulaciones porque no agrupan a la totalidad de las empresas anunciantes sino que únicamente rigen a aquéllas con la voluntad de cooperar con los principios que consagran; dejando fuera a un amplio núme-

44 Rodríguez Genteno, Juan Carlos, "La Responsabilidad Social Corporativa. Nuevos Contenidos para la Comunicación Empresarial" en Questiones Publicitarias Revista Internacional de Comunicación y Publicidad, Vol. 1, núm. 10, 2005, p. 144.

45 Argentina cuenta con un Código de Ética y Autorregulación Publicitaria adoptado por el Consejo de Autorregulación Publicitaria (CONARP). Por su parte, en México, la Asociación Nacional de Publicidad (ANP) cuenta con un Código de Ética. Del mismo modo, en Venezuela existe un con Código de Ética Publicitaria; y a su vez Puerto Rico dispone de un ordenamiento político normativo en materia de publicidad adoptado por la Asociación de Agencias Publicitarias de Puerto Rico. En todos los casos, si bien existen referencias expresas a la no discriminación, particularmente los códigos argentino y puertorriqueño resultan ser los más completos en la medida en que introducen una protección específica relacionada con los distintas formas en que pueden transmitirse anuncios publicitarios. 
ro de entidades comerciales que transmiten mensajes por conducto de los MGM.

Una forma de hacer frente a esta problemática puede ser la implementación de estímulos por parte del gobierno que permitan promover y fomentar prácticas y comportamientos voluntarios y socialmente responsables por parte de las empresas anunciantes, agencias publicitarias y medios de comunicación. Dichos estímulos pueden materializarse en la obtención de mayores puntajes en el proceso de licitaciones públicas; en el acceso a créditos superiores a favor de micro y pequeñas empresas; en el reconocimiento estatal a favor de empresas que cumplan con dichas prácticas; en la adquisición de mayor tiempo radio espacial para la transmisión de anuncios publicitarios así como en la obtención de deducciones tributarias adecuadamente reguladas. ${ }^{46}$ El otorgamiento de dichos incentivos por parte del gobierno, puede constituir, a su vez, una práctica congruente con el principio de protección de los derechos humanos que tiene a su cargo en el ámbito de las relaciones entre el Estado y las empresas. ${ }^{47}$

En el plano internacional, hace algunos años el que fuera Secretario General de la Organización de las Naciones Unidas (ONU), Kofi Annan, dio cuenta de la necesidad de que las empresas comenzaran a adoptar una serie de directrices que les permitieran asumir compromisos relacionados con el respeto y observancia de los derechos humanos. Durante la Cumbre Económica Mundial de

46 En el caso de Colombia, actualmente el Senado discute el Proyecto de Ley $\mathrm{N}^{\circ}$ 70/2010 "por la cual se definen normas sobre la responsabilidad social empresarial, la protección infantil y se dictan otras disposiciones". Dicho proyecto pretende promover la responsabilidad social de las empresas a fin de que éstas diseñen e implementen programas que tiendan al logro de objetivos sociales como la protección de la niñez, la erradicación del trabajo infantil y el respeto de los derechos humanos. Vid. Congreso de la República de Colombia, Proyecto de Ley 70 de 2010 Senado, publicado en la Gaceta del Congreso 494, 5 de agosto de 2010 disponible en: <http://servoaspr.imprenta.gov.co:7778/gacetap/gaceta.nivel_3>.

47 Vid. infra, p. 22. 
Davos en 1999, el Secretario General de la ONU invitó a las empresas de todo el mundo a que sometieran sus actividades al tenor de nueve principios emanados de la Declaración Universal de los Derechos Humanos, de la Declaración sobre los Principios y Derechos Fundamentales de la Organización Mundial del Trabajo, de la Declaración de Copenhague y de la Declaración de Río de la Conferencia de Naciones Unidas sobre Desarrollo y Medioambiente. En conjunto, tales principios integrarían en un inicio lo que hoy se conoce como Pacto Mundial, el cual no constituye un documento de carácter normativo o de supervisión, sino que se ubica en el plano de los documentos susceptibles de ser utilizados en los procesos de autorregulación empresarial; razón por la que no existen mecanismos de supervisión directa ni de establecimiento de sanciones o repercusiones derivadas su incumplimiento o inobservancia. ${ }^{48}$

El Pacto Mundial se integra por ejes principales relacionados con los derechos humanos, las condiciones laborales y el medio ambiente que en un primer momento incorporaban nueve principios rectores. Sin embargo, en el año 2004 los participantes de la Cumbre de Líderes del Pacto Mundial, celebrada en Nueva York, decidieron incluir un principio más relacionado con el combate a la corrupción; esta situación trajo como consecuencia una reestructuración de dicho Pacto de modo que en la actualidad se integra por un total de 10 principios rectores divididos en cuatro ejes principales, a saber: derechos humanos, estándares laborales, medio ambiente y anticorrupción. ${ }^{49}$

Con el objetivo de ejemplificar el alcance e impacto que ha tenido el Pacto Mundial en el ámbito mexicano, cabe señalar que a la fecha existen 678 instituciones mexicanas participantes en dicho pacto de

48 ONU, Centro de Información de las Naciones Unidas para México (CINU), ¿Qué es el Pacto Mundial?” Disponible en: <http://www.cinu.org.mx/pactomundial/index.htm>, página consultada el 13 de novimebre de 2014.

49 ONU, United Nations Global Compact, Los Diez Principios del Pacto Mundial. 
la cuales 393 corresponden al ámbito empresarial ${ }^{50}$ y únicamente 14 se encuentran relacionadas con los MCM. ${ }^{51}$ En este contexto, es posible observar cómo tanto a nivel nacional e internacional se han intentado desarrollar mecanismos de autorregulación dirigidos de manera general a las empresas y, por extensión, a aquellas relacionadas con actividades publicitarias y MCM. Si bien dicho desarrollo ha servido como base para generar estructuras que permitan el fortalecimiento de una sociedad caracterizada por el respeto de los derechos humanos, es una realidad que el alcance y cumplimiento de dichos mecanismos se ven muchas veces limitados por la falta de voluntad o información a cargo de las empresas; por lo que cobra relevancia el análisis relacionado con el papel del Estado en la regulación de las empresas publicitarias a través de leyes y políticas públicas.

2. Principios Rectores del Estado y de las empresas en EL ÁMBITO DE LA PUBLICIDAD COMERCIAL DESDE UN ENFOQUE DE DERECHOS HUMANOS

Durante los últimos años, el papel de las empresas en el ámbito de derechos humanos ha sido foco de atención y análisis por parte

50 Es importante precisar que la adhesión al Pacto Mundial no se circunscribe únicamente a las empresas de carácter comercial, sino que instituciones públicas, organizaciones no gubernamentales, sindicatos y universidades pueden asumir el compromiso voluntario de dirigir sus acciones a la luz de los principios contenidos en él.

51 Las empresas mexicanas adheridas al Pacto Mundial en el ramo de los medios de comunicación son: P1stache; Diformex S.A de C.V; Rótula S.A de C.V; Adivor S.C.P; Operadora Expresa S.A de C.V; Cia. Periodística del Sol de Chihuahua S.A de C.V; Mega Medios S.A de C.V y Alkima Marketing Group. Esta información fue obtenida del buscador oficial de la página electrónica del Pacto Mundial a partir de la búsqueda específica por país disponible en < https:/ / www.unglobalcompact.org/participants/search? utf8=\%E2\%9C\%93\&commit=Search\&keyword=\&country $\% 5 \mathrm{~B} \% 5 \mathrm{D}=138 \&$ joined_after $=\&$ joined_before $=\&-$ business_type=2\&sector_id=46\&listing_status_id=all\&cop_status=all\&organization_type_id=\&commit=Search $>$, página consultada el 13 de noviembre de 2014 . 
de organismos internacionales de promoción y defensa de derechos humanos. Esta situación responde al hecho de que en la actualidad las empresas desempeñan un papel protagónico en la vida de la sociedad al establecer relaciones de diversos tipos con las personas que la integran. Ejemplo de ello lo constituye la obligación de respetar los derechos laborales de las personas que trabajan para determinada compañía o la obligación dirigida a las empresas de contratar a personas con discapacidad o personas adultas mayores para la realización de actividades acordes con las capacidades y aptitudes de cada una de ellas. Asimismo, el papel de las empresas en materia de derechos humanos se ha diversificado en la medida en que son cada vez mayores las políticas o leyes que obligan a las empresas a adoptar actitudes de compromiso y respeto hacia algunos derechos humanos como el medio ambiente a través del fomento de la utilización de materiales biodegradables para la fabricación de productos o la obligación de consultar a pueblos o comunidades indígenas cuando se trate de actividades o proyectos a gran escala para la explotación de recursos naturales.

Desafortunadamente, en materia de publicidad aún no existen suficientes ordenamientos jurídicos que aseguren el respeto y la promoción de derechos humanos por parte de las empresas o de los MCM sino que la mayoría de las acciones emprendidas en este rubro son de carácter potestativo a través de la iniciativa o de las políticas institucionales de cada empresa (mecanismos de autorregulación). Pese a ello, el respeto y promoción de derechos humanos por parte de las empresas anunciantes no puede quedar únicamente a su arbitrio sino que se requiere de una constante y amplia participación del Estado. Es decir, es una tarea que debe realizarse de manera conjunta entre el Estado y las empresas constituidas en su territorio y que operen o tengan algún alcance en el mismo.

En este sentido, el Representante Especial del Secretario General de la Organización de las Naciones Unidas para la cuestión de los Derechos Humanos y las Empresas Transnacionales y Otras 
Empresas, John Ruggie, ha señalado que existen tres principios rectores dirigidos al Estado y a las empresas que deben cumplirse para asegurar la salvaguardia en el goce y ejercicio de los derechos humanos de todas las personas. ${ }^{52}$ En el ámbito de la publicidad, tales principios pueden aplicarse de la siguiente manera:

1) Principio de Proteger: Este principio se traduce en la obligación del Estado de ofrecer protección frente a los abusos de derechos humanos cometidos por terceros, incluidas las empresas, mediante medidas adecuadas, actividades de reglamentación y sometimiento a la justicia. ${ }^{53}$

Siguiendo este principio, el Estado tiene la obligación de emprender todo tipo de acciones, ya sean de carácter ejecutivo, legislativo o judicial, a efecto de regular la actuación de las empresas anunciantes para que aseguren la promoción y el respeto de los derechos humanos y evitar que, a través de la publicidad que se transmita en los MCM, vulneren o afecten tales derechos.

No obstante, tal parece que las disposiciones legales que regulan el ejercicio de los MGM, en relación con la publicidad, se han inclinado únicamente a establecer prohibiciones a las empresas, agencias publicitarias y MCM para impedir que éstas transmitan mensajes que puedan atentar contra los ideales o valores de la comunidad. Esta regulación no resulta suficiente para conseguir el fin establecido de proteger y promover derechos humanos, toda vez que únicamente cubre una arista consistente en una obligación de no hacer.

52 Vid. ONU, Informe del Representante Especial del Secretario General para la cuestión de los derechos humanos y las empresas transnacionales y otras empresas, Fohn Ruggie. Principios Rectores sobre las empresas y los derechos humanos: puesta en práctica del marco de las Naciones Unidas para "proteger, respetar y remediar", aprobado por el Consejo de Derechos Humanos de las Naciones Unidas en su resolución A/HRC/17/31 durante su XVII periodo de sesiones, Ginebra, Suiza, 21 de marzo de 2011.

53 Ibidem, p. 4. 
Por ello, para que el Estado dé total cumplimiento al principio rector de proteger, es necesario que impulse políticas públicas y leyes que garanticen la promoción de derechos humanos por medio de anuncios publicitarios a cargo de las empresas anunciantes. Es decir, no basta con una política de abstención, sino que se requiere una política de acción consolidada y estructurada que permita alcanzar un pleno y efectivo respeto a los derechos humanos, haciendo uso del impacto y alcance que tiene la publicidad a través de los MCM.

2) Principio de Respetar: Este principio marca la obligación de las empresas de respetar los derechos humanos, lo que significa actuar con la debida diligencia para no vulnerar los derechos de terceros y reparar las consecuencias negativas de sus actividades. ${ }^{54}$

La responsabilidad de las empresas publicitarias en torno al respeto y promoción de derechos humanos, se traduce, prima facie, en el deber de verificar que los contenidos de sus mensajes no generen un impacto negativo en la comunidad o en las personas que la integran. Dicha obligación también implica que las empresas anunciantes adopten medidas tendientes a lograr que se incluyan mensajes que promuevan el contenido y respeto a derechos humanos.

Lo anterior sólo podrá lograrse en la medida en que las empresas anunciantes asuman un compromiso político y realicen un análisis previo del contenido de sus anuncios publicitarios, a través de un proceso de asesoramiento incluyente que permita la participación de personas expertas en derechos humanos, de grupos en situación de vulnerabilidad, de integrantes de la sociedad civil y de instituciones gubernamentales.

3) Principio de Remediar: Constituye la necesidad de mejorar el acceso de las víctimas de violaciones a derechos hu-

54 Idem. 
manos a vías de reparación efectivas, tanto judiciales como extrajudiciales. ${ }^{55}$

La obligación enunciada en este principio va encaminada a que el Estado brinde los mecanismos adecuados y efectivos que permitan a las personas exigir el cumplimiento de las leyes y mecanismos de control que se hayan emitido en relación con el ejercicio responsable de la publicidad. En este rubro, el papel de los organismos jurisdiccionales y de los organismos de protección a los derechos humanos cobra total relevancia en la medida en que éstos serán quienes determinen si existe o no una vulneración a los derechos de las personas y de la sociedad derivada de alguna práctica publicitaria.

Uno de los beneficios que podría derivar de la asimilación jurídica de los principios rectores dirigidos a las empresas y al Estado, es que dicha situación permitiría hacer frente a las críticas y deficiencias que caracterizan a los mecanismos de autorregulación empresarial en materia de publicidad; lo que redundaría en un control más efectivo respecto del actuar de las autoridades y empresas, así como del contenido de los anuncios publicitarios, haciendo posible exigir acciones adecuadas y tendientes a la reparación por violaciones o afectaciones a los derechos humanos. Pero tal vez lo más importante sea que la implementación y regulación normativa de los tres principios rectores antes señalados podrían generar un equilibrio entre el ejercicio de prácticas publicitarias a través de los MCM y el respeto y garantía de los derechos humanos dentro de una sociedad pues haría posible el desarrollo de actitudes comprometidas y responsables por parte del Estado, las empresas publicitarias y los MCM en donde cada uno de dichos actores adoptarían estrategias comunes de promoción en derechos humanos.

55 Idem. 
VI. LA PUBLICIDAD COMERCIAL COMO MECANISMO DE EDUCACIÓN Y PROMOCIÓN EN DERECHOS HUMANOS

Retomando los argumentos sobre el alcance e impacto que tiene la publicidad a través de los MCM, resulta imposible desconocer el papel potencial de transformación que puede desempeñar la publicidad en la ideología, las actitudes y los comportamientos de la sociedad en relación con los derechos humanos. En este sentido, la publicidad puede ser utilizada como un mecanismo de capacitación y difusión de información orientada a crear una cultura universal en la esfera de los derechos humanos mediante la transmisión de conocimientos, la enseñanza de técnicas y la formación de actitudes para promover el respeto a los derechos humanos, lo que la convertiría en una técnica y una herramienta de educación en derechos humanos. ${ }^{56}$

La publicidad puede promover la educación en derechos humanos a través de la eliminación de estereotipos y prejuicios derivados de condiciones o preferencias sociales tales como la religión, la raza, la orientación sexual, la nacionalidad; así como a través de la inclusión de grupos que, por su situación especial de vulnerabilidad, se encuentren excluidos o marginados del ámbito social, jurídico, laboral, económico o cultural en una comunidad. Desde esta perspectiva, hoy en día es común apreciar a través de los MCM anuncios publicitarios con un claro contenido discriminatorio hacia las mujeres en los que se les ubica en roles y actividades caracterizadas por estereotipos arraigados en una cultura machista o en los que se les muestra como un objeto sexual que los hombres pueden

56 Vid. Proyecto revisado del plan de acción para la primera etapa (2005-2007) del Programa Mundial para la educación en derechos humanos. Asamblea General de las Naciones Unidas, quincuagésimo noveno periodo de sesiones, A/59/525/Rev. 1 . 
poseer. ${ }^{57}$ Esta situación ha sido analizada con mayor precisión en España, donde de acuerdo con datos del Observatorio Andaluz de la Publicidad No Sexista, las empresas que promocionan productos de salud y belleza masculina como desodorantes, shampoos, cremas de afeitar, rasuradoras, entre otros, son las más denunciadas por las y los usuarios por transmitir mensajes publicitarios con altos contenidos sexistas. ${ }^{58}$ De igual forma, en México, el Consejo Nacional para Prevenir la Discriminación (CONAPRED) ha documentado alrededor de 85 quejas sobre presuntos actos de discriminación en contra de mujeres en MCM. ${ }^{59}$

En este contexto de discriminación en contra de las mujeres, un ejemplo que podría caracterizar a la publicidad como mecanismo de educación en derechos humanos sería la transmisión de anuncios en MCM de ciertos productos como detergentes en los cuales la imagen principal sea la de un hombre que realice una labor que durante mucho tiempo se ha creído es única para las mujeres. De esta forma, se estaría en la posibilidad de eliminar un prejuicio basado en un estereotipo de género. Esta situación ya fue abordada por la marca Henkel Ibérica S. A. en España quien al momento de

57 Vid., Conapred, Boletín de Prensa 057/2011 "Persiste discriminación hacia las mujeres dentro de la publicidad: Conapred - Inmujeres", 12 de septiembre de 2011, disponible en <http://www.conapred.org.mx/index. php? contenido=boletin\&id=378\&id_opcion $=103 \& o p=213>$.

58 Vid. Observatorio Andaluz de Publicidad No Sexista. Informe Anual 2011, Instituto Andaluz de la Mujer, Consejería para la Igualdad y Bienestar Social, Andalucía, España, 2011.

59 Esta información fue obtenida a partir de una solicitud de acceso a la información pública en la que se preguntó a dicho organismo si contaba con algún mecanismo para la recepción de quejas por anuncios discriminatorios transmitidos en MCM; el número de quejas recibidas; los grupos principalmente afectados y el trámite y estado de cada una de las quejas. La solicitud de información fue recibida por el organismo el 3 de julio de 2012 y respondida a través del oficio CONAPRED/DGAQyR/163/2012 el 17 de julio del mismo año. 
anunciar un detergente para ropa utilizó la imagen de un hombre como protagonista del anuncio publicitario. ${ }^{60}$

Todo este tipo de manifestaciones relacionadas con la publicidad comercial y derechos humanos han llevado a que en España, por ejemplo, las autoridades hayan adoptado diversas disposiciones normativas que regulan precisamente la transmisión de mensajes e ideas publicitarias -sobre todo aquellas con contenido machista o sexista- como la Ley Orgánica 1/2004 cuyo Título I, Capítulo III, hace mención expresa del papel que debe desempeñar la publicidad comercial señalando que será ilícita toda aquella publicidad que muestre a las mujeres con carácter vejatorio o discriminatorio. Asimismo, dicha ley apunta que los MCM deben transmitir mensajes que fomenten la protección y salvaguardia de la igualdad entre hombres y mujeres, evitando de mayor manera actitudes de discriminación. ${ }^{61}$

En un plano similar, las personas pertenecientes a la comunidad lésbico, gay, bisexual, transexual, travesti, transgénero e intersexual (LGBTI), al igual que las mujeres, constituyen un grupo social que se enfrenta a un escenario de discriminación en el marco de la publicidad comercial, ${ }^{62}$ caracterizado también por las concepciones e ideas que rigen a sociedades machistas y heterocentradas. Es una realidad que en la mayoría de las sociedades aún no se transmiten anuncios publicitarios que presenten contenido homosexual (principalmente en televisión); lo cual hace posible que la sociedad siga

60 Ibidem.

61 Ley Orgánica 1/2004 de 28 de diciembre de 2004, Medidas de Protección Integral contra la Violencia de Género, publicada en el Boletín Oficial del Estado (BOE) el 29 de diciembre de 2004, BoE núm. 313.

62 De acuerdo con información del Consejo Nacional para Prevenir la Discriminación (CONAPRED), las personas de la diversidad sexual son las más afectadas por la transmisión de mensajes discriminatorios en MCM en México, pues dicho organismo ha registrado un total de 188 quejas por actos presuntamente discriminatorios vinculados con medios de comunicación. vid., solicitud de acceso a la información pública, n. 57. 
adoptando y arraigando patrones estigmatizantes en contra de las personas que pertenecen a dicha comunidad y que perpetuan actitudes de intolerancia y discriminación hacia ellas.

En la actualidad, son pocas las empresas que anuncian sus productos o marcas a través de anuncios publicitarios con contenido homosexual y la gran mayoría de ellas lo hace a través de medios de comunicación impresos como revistas o incluso a través de Internet. Sobre este particular, vale la pena señalar que, en gran medida, son las marcas de ropa las que promueven actitudes de respeto y visibilización de los derechos humanos de las personas homosexuales; a manera de ejemplo podrían señalarse casos como los de la marca de ropa Dolce \& Gabanna la cual ha cobrado mayor fama por la utilización de modelos homosexuales que expresan actitudes de la misma naturaleza. Otras marcas que han utilizado este tipo de estrategias publicitarias son RayBan, Levis, GAP y JC Penney.

Respecto a la comunidad LGBTI, la publicidad puede jugar un papel trascendental en lo que respecta a la promoción y respeto de sus derechos humanos mediante la transmisión de anuncios publicitarios que contribuyan a la erradicación de patrones discriminatorios sobre la base de la orientación o la preferencia sexual de las personas, así como sobre los distintos estilos de vida que deseen adoptar y que impacten en la configuración de identidades personales, sociales y familiares. La publicidad comercial puede ser un mecanismo de utilidad para eliminar la concepción generalizada que se tiene sobre la familia a partir de su integración heterosexual por medio de anuncios publicitarios que expresen la conformación familiar de parejas homosexuales y la posibilidad de éstas de adoptar a niñas y niños.

En este sentido, la campaña publicitaria de la conocida tienda estadounidense de ropa JC Penney es un ejemplo de publicidad con enfoque de derechos humanos a favor de la integración familiar de personas homosexuales. Con motivo de la celebración del día de la madre y del padre, dicha tienda lanzó dos anuncios publicitarios 
que mostraban a familias integradas por madres y padres homosexuales en compañía de sus hijas e hijos. Dicha campaña publicitaria no tardó en generar reacciones en la sociedad, sobre todo en las corrientes más conservadoras y religiosas, pues la organización de madres One Million Moms comenzó una campaña de denuncia y sabotaje en contra de la empresa, argumentando que su publicidad atentaba contra los valores de dios y la Biblia. La organización One Million Moms ha llevado acabo acciones similares en contra la marca GAP denunciando su campaña publicitaria Be One que, al igual que la de JC Penney, muestra a parejas homosexuales. ${ }^{63}$

Pese a lo señalado anteriormente, no es posible perder de vista que la publicidad con enfoque homosexual, en algunos casos, puede fomentar también actitudes de discriminación u homologación de identidades o patrones físicos y sociales que no necesariamente respondan de manera objetiva a los distintos conceptos y modelos de homosexualidad. Por ello, es importante que las empresas que realicen prácticas publicitarias desde un enfoque de derechos LGBTI sean conscientes y responsables de no imponer un estilo o modelo único de sexualidad, invisibilizando así los estilos de vida de otras personas o grupos pertenecientes a dicha comunidad.

Por último, y sin la intención de entrar a un análisis específico de otros grupos en situación de vulnerabilidad, es importante hacer mención que la publicidad comercial, al igual que lo hace con las mujeres y las personas pertenecientes a la comunidad LGBTI, puede ayudar a que las personas indígenas, las y los niños, las personas adultas mayores, las personas con discapacidad y las minorías étnicas perciban un entorno de mayor inclusión y no discriminación en la sociedad en la que se inscriben.

63 La información relativa a las acciones emprendidas por la organización One Million Moms puede consultarse en la siguiente página de Internet: <http:// onemillionmoms.com/>. 
vil. Conclusiones

El discurso comercial, al encuadrarse en la protección otorgada por los derechos a la libertad de expresión y de información, se coloca como un elemento que resulta de necesidad e importancia en el marco de una sociedad democrática, pues su ejercicio, más allá de fomentar prácticas de consumo entre las personas, también otorga herramientas valiosas que permiten la modificación estructural de situaciones generadoras de injusticia social. La utilización de la publicidad comercial para la consecución de tales fines ofrece ventajas importantes en relación con otros mecanismos de comunicación tales como el carácter persuasivo que la caracteriza, su producción cada vez más sistematizada, el alcance que ésta puede tener con el apoyo de los medios de comunicación masiva, las formas y técnicas creativas utilizadas para captar la atención de las personas, para generar mecanismos de aprehensión e identificación y, por ende, para obtener respuestas deseadas en menor tiempo.

Gracias a la utilización e implementación adecuada de las características antes mencionadas, es que la situación de los derechos humanos dentro la sociedad puede mostrar cambios significativos en beneficio de distintos grupos y personas en situación de vulnerabilidad. Esto trae como consecuencia necesaria el fortalecimiento de las bases que permitan consolidar una sociedad más inclusiva, plural, tolerante y respetuosa de las características y diferencias de cada persona y grupo, promoviendo así un ambiente armonioso en el que las personas puedan desarrollarse de manera óptima. Sin embargo, es importante también sobreponerse a aquella concepción que ubica al ejercicio de la publicidad comercial desde la perspectiva de derechos humanos como una carga o deber desproporcionado impuesto a las empresas anunciantes y como una intromisión en la toma de decisiones y en el ejercicio de sus políticas institucionales. Las empresas deben adoptar conciencia en cuanto a que el cumplimiento de dichas obligaciones podría traerles importantes beneficios en la 
percepción que la sociedad tenga de sus productos o marcas y, por ende, en el incremento de sus ventas y ganancias económicas. No obstante, estos beneficios no necesariamente se encuentran dirigidos únicamente a las grandes empresas, sino que la implementación de políticas y programas institucionales por parte de pequeñas y medianas empresas, también, pueden generarles posibilidades de apoyo o financiamiento por parte del Estado, siempre que para ello exista una adecuada regulación de incentivos y estímulos empresariales.

En la medida en que las personas den cuenta que una determinada marca o empresa promueve y desarrolla un compromiso con ellas y con sus derechos fundamentales, posiblemente provoque que adquieran dichos productos en mayor medida. De esta forma, la publicidad como mecanismo de educación y promoción en derechos humanos podría llevar a las empresas anunciantes, agencias publicitarias y MCM a desarrollar, como efecto secundario y no intencional, una publicidad de tipo corporativo, la cual tiene como objetivo establecer una actitud favorable hacia la empresa por parte de la sociedad o comunidad. ${ }^{64}$ Por su parte, el Estado y sus autoridades también deben adoptar medidas adecuadas de cualquier índole con el objetivo de asegurar no sólo que las empresas anunciantes y los medios de comunicación masiva no transmitan mensajes que atenten contra el goce y ejercicio de los derechos humanos de las personas sino que además deben desarrollar mecanismos adecuados que hagan posible que dichos actores promuevan el respeto y la tolerancia de todas las características, identidades y formas de vida que tienen cabida en una sociedad plural y no precisamente homogénea. En este sentido, el desarrollo y los avances logrados a nivel internacional, así como por tribunales constitucionales de distintos Estados, constituyen referentes indispensables a utilizar al momento de que las autoridades analicen e interpreten el ejercicio de la publicidad comercial desde un enfoque de derechos humanos.

64 O’guinn, Thomas, Allen, Chris, y Semenik, Richard, Publicidad, Ed. Internacional Thomson Editores, 1999, pp. 555 y 556. 